\title{
'N KOMMUNIKATIEFGEFUNDEERDE ONDERSOEK NA BEPAALDE WAARNEMINGSVERSKYNSELS BY DISFEMIE
}

\author{
RENÉ HUGO M.A. (LOG.) (Pretoria) \\ Spraak, Stem-en Gehoorkliniek, Universiteit van Pretoria
}

\section{OPSOMMING}

Hierdie studieprojek stel hom ten doel die bestudering van bepaalde ouditiewe waarnemingsvermoëns by disfemie, soos gesien vanuit 'n kommunikatiewe oogpunt.

Eksperiment 1: stel hom ten doel die bepaling van suiwertoonsensitiwiteit en spraakdiskriminasievermoëns van 'n groep van 10 hakkelaars, en die vergelyking van hierdie gegewens met 'n kontrole groep nie-hakkelaars. Die resultaat dui op 'n betekenisvolle verskil, tussen die suiwertoondrempelwaardes van die regterore van die hakkelaars en nie-hakkelaars en kan moontlik in verband gebring word met sowel terugvoeringsafwykings as gehoordominansieteorieë.

Eksperiment 2: beoog die bepaling van waarnemingsdrempels van neutrale en negatiewe woorde (woorde waarop gewoonlik gehakkel word) by 'n groep hakkelaars, en die vergelyking hiervan met 'n aantal nie-hakkelaars. Die resultate toon 'n betekenisvolle verskil tussen hierdie 2 lyste vir die hakkelaars, maar nie vir die vlotsprekers nie. Ter verklaring kan aangevoer word dat die hakkelaars, op grond van emosionele kwaliteite verbonde aan die negatiewe woorde, hierdie woorde makliker waarneem as die vlotspreker, waarskynlik deur gebruik te maak van perseptuele verdedigingsmeganismes soos perseptuele ingest emdheid.

Eksperiment 3: is gerig op die bepaling van die bestaan van onwaarneembaarheid van betekenisvolle stimuli by die hakkelaar tydens die hakkelperiode. Geen sodanige verskynsel kan betekenisvol aangetoon word nie, hoewel daar in die bespreking daarop gewys is dat 'n verandering in die eksperimentele prosedures nogtans so 'n fenomeen kan uitwys.

In sy geheel gesien, is daar dus in hierdie studieprojek bepaalde waarnemingsabnormaliteite by die disfemie aangetoon wat nie by die vlotspreker gevind kan word nie. Hierdie abnormaliteite dui essensieel op 'n wyer siening van disfemie nl., as 'n komplekse, kommunikatiewe probleem.

\section{SUMMARY}

In this study certain aspects of auditory perception in cases of dysphemia are studied, emphasis being on communication aspects.

Experiment 1: has as its object the determination of pure-tone sensitivity and speech discrimination abilities of a group of 10 stutterers, and the comparison of these data with a control group of non-stutterers. The results point to a significant difference between the pure-tone threshold values of the right ears of the stutterers and the non-stutterers, and may be linked with feedback deficiences and with theories on auditory dominance. 
Experiment 2: sets out to determine perceptual thresholds of neutral and negative words (words which are usually stuttered on) in the case of a group of stutterers, and to compare these threshold values with those of non-stutterers. The results show a significant difference between these two lists for the stutterers, but not for fluent speakers.

A suggested explanation is that the stutterers perceive negative words more readily than fluent speakers do, because of the emotional qualities connected with these words, probably by putting up perceptual defence mechanisms such as the perceptual set.

Experiment 3: aims, at the determination of the existence of imperceptivity with regard to meaningful stimuli in the case of the stutterer during the stuttering block. No such phenomenon can be proven, although in the discussion it is indicated that a variation of the experimental procedure may point to such a phenomenon.

In general this study thus presents certain perceptual abnormalities evidenced in dysphemia cases, which are not found in fluent speakers. These abnormalities clearly point to the need for a broader concept of dysphemia. It must be seen as a complex problem.

Edward Sapir ${ }^{9}$ het te kenne gegee: ,Human beings do not live in the objective world alone, nor alone in the world of social activity as ordinarily understood, but are very much at the mercy of the particular language which has become the medium of expression for their society".

Hierdie afhanklikheid word groter en verkry 'n definitiewe negatiewe kleur, sodra die taalvermoë bepaalde nie-normale verskynsels vertoon. Die verskynsel van disfemie kan waarskynlik as een van die grootste en mees omvattende abnormaliteite beskou word, omdat dit die kommunikasievermoë as geheel betrek. ${ }^{3}$

Daarom is dit aanvaarbaar om te verwag dat die motoriese herhalings- en verlengingsabnormaliteite ook ' $n$ sensoriese (perseptuele?) komponent moet hê. Selfs al word disfemie in die lig van 'n leerproses, eerder as 'n fisiese of neurale afwyking gesien, moet dit nogtans 'n sensoriese komponent besit as in ag geneem word dat Mowrer verklaar het: all learning takes place on the sensory side". ${ }^{3}$

Daar bestaan dan op die huidige stadium heelwat teorieë en bespiegelings wat hierdie gebied betrek. In 'n poging om al die uiteenlopende benaderings tot persepsieafwykings en disfemie as 'n eenheid te sien, kan die benadering van Freund as verteenwoordigend dien:

Persepsie-afwykings by die hakkelaar as spreker. In die verhouding tussen innerlike spraak en uiterlike hakkel, kan gevind word dat die bespeuring van 'n ,moeilike' woord op 'n baie vroeë sta dium van sinsamestelling plaasvind. Op 'n stadium wat die woord self onhoorbaar en onsigbaar is vir die innerlike oor, d.w.s., op 'n preverbale, preperseptuele stadium, kan die moontlike aanwesigheid van die woord alreeds deur leidrade van ongemak ervaar word. Op hierdie wyse kan modifikasie, in 'n poging tot vermyding, alreeds op 'n onbewuste vlak plaasvind. Dus: „Even in this 'deep' perceptual layer of inner speech, the complex of disturbances exerts its influence". 
Persepsie-afwykings by die hakkelaar as waarnemer. Die oomblik van hakkel gaan gepaard met 'n groot aantal perseptuele distorsies, $\mathrm{nl}$.:

i. Verkleining van die bewussynsveld;

ii. werklike perseptuele distorsies.

Ondersoekers soos Johnson en William het hierdie abnormaliteite as die natuurlike gevolg van die hakkelaar se foutiewe self-evaluasie verklaar. Freund beweer egter dat die foutiewe evaluasies sekondêr, en nie aanleidend is, tot die perseptuele distorsies nie.

Gedurende die hoogtepunt van hakkel is daar 'n gerigte affektief-outosuggestiewe aandagkonsentrering op die struikelblok. Hierdie konsentrasie is van so 'n intensiewe aard dat die gepaardgaande nodige perseptuele aksies verlore gaan.

Freund noem hierdie verskynsel „,kinesthetic illusion" en verklaar dit as die gevolg van 'n hoogs emosionele toestand waartydens 'n persoon sy hulpeloosheid ervaar in die aanwesigheid van onoorkomelike probleme. Hierdie terme is soortgelyk aan dié deur Hans W. Meur gebruik en deur Froeschels oorgeneem nl., ,catathymia" wat'die invloed van sterk affektief-belaaide kompleksiteite op bewustheid en persepsie impliseer. ${ }^{4}$

\section{METODE}

Dit word gehipoteseer dat die hakkelaar bepaalde ouditiewe waarnemingsabnormaliteite vertoon wat:

a) voorkom tydens die hakkelperiode;

b) die waarnemingsdrempèl sal beïnvloed.

Hierdie verskynsels sal waarskynlik nie aanwesig wees by die nie-hakkelaar nie. Daar sal gepoog word om aan te toon dat hierdie waarnemingsabnormaliteite, indien dit wel voorkom, nie so afwykend is as wat aanvanklik gemeen is nie. Dit hou eerder verband met ,normale" verdedigingsmeganisme - in soverre as wat verdedigingsmeganisme as normaal beskryf kan word - teen dreigende stimuli.

\section{Probleemstelling}

Dit is van 'n drievoudige aard $\mathrm{nl}$.:

1. Is die suiwertoonkurwe en spraakdiskriminasievermoëns van die hàkkelaar vergelykbaar met dié van die nie-hakkelaar? Indien nie, op watter gebiede sal hierdie verskille voorkom?

2 . Is daar 'n verskil tussen die waarnemingsdrempel van neutrale en emosioneeldreigende woorde by die hakkelaar? Kom hierdie verskil, indien dieselfde woorde gebruik word, ook by die nie-hakkelaar voor?

3. Toon die hakkelaar bepaalde onwaarneembaarheidskenmerke tydens die hakkelperiode? Indien wel, kan dit in verband gebring word met die aard van die stimuli? 


\section{APPARAAT}

Die Maico M.A. 24 dubbelkanaal-oudiometer (standaard I.S.O.) geleë in 'n klankdigte tweekamer-kompleks kamer, is gebruik.

\section{PROEFPERSONE}

1. Eksperimentele groep - bestaan uit 'n groep van 10 hakkelaars tussen die ouderdomme 16-31 jaar. Die groep is verkry uit verwysings van die Spraak-, Stem- en Gehoorkliniek, Universiteit van Pretoria. Omdat die eksperimente 'n redelike mate van insig in die probleem vereis, is slegs dié hakkelaars geselekteer wat 'n deelname in terapie het en wat deur hul terapeut as volwasse gedefinieer is.

2. Kontrolegroep - bestaan uit 10 nie-hakkelaars, ook tussen die ouderdom van 16-31 jaar. Hierdie groep is geselekteer met die doel om te verseker dat hulle homogeen in alle opsigte is, in vergelyking met die eksperimentele groep, behalwe vir die element van vlotheidsversteuring. Om dit te verseker, is gebruik gemaak van die metode van afgepaarde vergelykings waar die volgende faktore konstant gehou is: ouderdom, geslag, intellektuele peil, sosio-ekonomiese klas en swangerskappe.

\section{EKSPERIMENTE.}

Drie verskillende eksperimente word uitgevoer, en in hierdie verslag sal die eksperimente apart behandel word.

\section{EKSPERIMENT I}

Doel: Die bepaling van suiwertoonsensitiwiteit en spraakdiskriminasievermoëns.

\section{Materiaal:}

i. Vir die suiwertoontoets is gebruik: 'n suiwertoonoudiogram wat frekwensies $125,250,1000,2000,4000,8000 \mathrm{~Hz}$ asook die intensiteitsvlak $0.110 \mathrm{~dB}$-gehoorpeil (ISO. 1964) aandui. Hierdie oudiogram is vir elke oor afsonderlik gemeet en laat toe vir optekening van luggeleidings-, beengeleidings- en smalbandmaskeringswaarde.

ii. Vir die spraakdiskriminasietelling: 6 fonetiesgebalanseerde woordelyste van 25 woorde elk opgestel deur die WNNR (1962) is gebruik. Daar is gepoog om hoofsaaklik een waarde te bepaal nl., $100 \%$ korrekte spraakdiskriminasie.

\section{Metode:}

i. Soos gebruik vir die suiwertoontoets. Die aanbieding is by $1000 \mathrm{~Hz}$ begin, gevolg deur die lae frekwensies, weer $1000 \mathrm{~Hz}$ om die eerste bepaling te bevestig en laastens die hoë frekwensies. Die intensiteitsvermeerdering het in diskrete stappe van $5 \mathrm{~dB}$ plaasgevind. Die drempel (def: dié intensiteitsvlak waar die proefpersoon $50 \%$ reageer op die stimulusaanbiedinge) is bepaal deur 'n kombinasie van die stygende en dalende metode. 
ii. Soos gebruik vir die spraakdiskriminasietelling. Die aanbieding is begin by ' $n$ intensiteitswaarde ongeveer 20-30 dB bokant die gemiddelde suiwertoonkurwe. Verdere verhogings/verlaging het berus op die reaksie van die proefpersoon totdat die persentasiewaardes $50-100 \%$ gedek is.

\section{Resultaat (i)}

Die resultate word in Tabel I uitgelê:

\begin{tabular}{|c|c|c|c|}
\hline $\begin{array}{l}\text { Proef } \\
\text { persone. }\end{array}$ & Geslag & Regteroor & Linkeroor \\
\hline 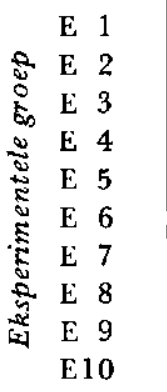 & $\begin{array}{l}M \\
M \\
V \\
M \\
M \\
M \\
M \\
V \\
V \\
M\end{array}$ & $\begin{array}{r}6,67 \\
11,67 \\
8,33 \\
13,33 \\
23,33 \\
0,00 \\
6,67 \\
11,67 \\
6,67 \\
13,33\end{array}$ & $\begin{array}{r}5,00 \\
11,67 \\
10,00 \\
73,33 \\
10,00 \\
1,67 \\
5,00 \\
10,00 \\
5,00 \\
15,00\end{array}$ \\
\hline 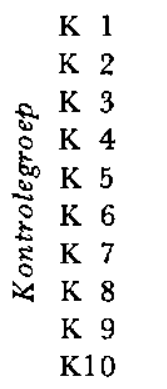 & & $\begin{array}{r}10,00 \\
6,67 \\
6,67 \\
3,33 \\
8,33 \\
5,00 \\
3,33 \\
3,33 \\
5,00 \\
8,33\end{array}$ & $\begin{array}{r}11,67 \\
8,33 \\
5,00 \\
5,00 \\
5,00 \\
11,67 \\
1,67 \\
1,67 \\
5,00 \\
5,00\end{array}$ \\
\hline
\end{tabular}

Tabel I Gemiddelde suiwertoon luggeleidingsdrempel in $a B$ van frekwensies 512, 1024, $2048 \mathrm{~Hz}$.

Ter verklaring van hierdie gegewens is dan gepoog om aandag aan die volgende resultaatverwerkings te gee:

1. 'n Vergelyking tussen die gemiddelde suiwertoondrempelwaardes van die linker- en regterore van die eksperimentele groep, waartydens die nulhipotese, dat daar geen verskil tussen hierdie ore bestaan nie, gestel is. Geen betekenisvolle verskil kan, wat betref die suiwertoondrempelwaardes, tussen die linker- en regterore van die eksperimentele groep aangetoon word deur toepassing van die tekentoets nie. 
2. 'n Vergelyking tussen die gemiddelde suiwertoondrempelwaardes van die regterore van die eksperimentele en kontrolegroepe. Met behulp van die Mann-Whitney-Wilcoxon-toets kan angetoon word dat die suiwertoondrempelwaardes van die regterore van die eksperimentele groep verskil, op die $2 \%$-peil van betekenis, van dié van die kontrolegroep.

3. 'n Vergelyking tussen die gemiddelde suiwertoondrempelwaardes van die linkerore van die eksperimentele en kontrolegroepe. In hierdie geval egter kan geen beduidende verskil d.m.v. die Mann-Whitney-Wilcoxon-toets aangetoon word nie.

4. 'n Vergelyking tussen die gemiddelde suiwertoondrempelwaardes van mans en vrouens van die eksperimentele groep. Die gebruik van statistiese verwerkings is in hierdie geval nie wenslik nie, hoofsaaklik as gevolg van die té klein aantal proefpersone wat tot ongemagtigde gevolgtrekkings kan lei.

Wat hierdie aspek betref kan daar dus volstaan word met verwysing na die feit dat daar korresponderende drempelwaardes vir die vroulike lede van die eksperimentele groep, die mans van die eksperimentele groep en ook die kontrolerende groep, bestaan.

\section{AFLEIDINGS (i)}

Samevattend wil dit dus voorkom asof daar wel 'n verskil tussen die suiwertoonsensitiwiteit van die hakkelaar en die nie-hakkelaar bestaan. Uit hierdie eksperiment word die verskil slegs vir die regterore aangetoon - 'n feit wat moontlik betekenisvol kan saamhang met ander toepaslike faktore soos liggaamsvoorkeur en hemisfeerdominansie. Voordat dit egter volkome aanvaar kan word, moet in aanmerking geneem word dat die eerste verwerking nl., 'n vergelyking tussen die regter- en linkerore van die eksperimentele groep, geen betekenisvolle verskille aangetoon het nie.

\section{RESULTAAT (ii)}

Met betrekking tot die tweede deel van eksperiment $1 \mathrm{nl}$., die bepaling van spraakdiskriminasievermoëns, is veral op twee waardes, $100 \%$ en $50 \%$ gelet. Dit is aangevul met ' $n$ verskil tussen die twee persentasiewaardes in 'n poging om die verloop van die spraakkurwe numeries voor te stel. Die resultate word in Tabel II uitgelê.

\section{AFLEIDINGS (ii)}

Hoewel statistiese verwerkings in hierdie geval moeilik gedoen kon word a.g.v. die voorkoms van 'n groot aantal gelyke waardes, wil dit tog oor die algemeen voorkom asof daar nie 'n betekenisvolle verskil tussen die verskillende gegewens aangetoon kan word nie.

\section{EKSPERIMENT II}

Doel: Die bepaling van die waarnemingsdrempel van bepaalde neutrale en 


\begin{tabular}{|c|c|c|c|c|c|c|c|c|}
\hline \multirow{3}{*}{\multicolumn{2}{|c|}{$\begin{array}{c}\text { Proef- } \\
\text { persone }\end{array}$}} & \multirow{3}{*}{ Geslag } & \multicolumn{6}{|c|}{ Intensiteitspeil in desibel } \\
\hline & & & \multicolumn{3}{|c|}{ Regteroor } & \multicolumn{3}{|c|}{ Linkeroor } \\
\hline & & & $100 \%$ & $50 \%$ & Verskil & $100 \%$ & $50 \%$ & Verskil \\
\hline \multirow{10}{*}{ 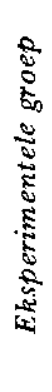 } & E 1 & $\mathbf{M}$ & 30 & 15 & 15 & 30 & 15 & 15 \\
\hline & E 2 & M & 40 & 20 & 20 & 30 & 15 & 15 \\
\hline & E 3 & $\mathrm{~V}$ & 30 & 15 & 15 & 30 & 15 & 15 \\
\hline & E 4 & M & 40 & 25 & 15 & - & - & - \\
\hline & E 5 & M & 50 & 35 & 15 & 40 & 20 & 20 \\
\hline & E 6 & M & 30 & 15 & 15 & 20 & 15 & 5 \\
\hline & E 7 & M & 30 & 20 & 10 & 30 & 15 & 15 \\
\hline & E 8 & V & 30 & 15 & 15 & 30 & 15 & 15 \\
\hline & E 9 & $\mathrm{~V}$ & 30 & 10 & 20 & 20 & 15 & 5 \\
\hline & E10 & $M$ & 30 & 15 & 15 & 30 & 10 & 20 \\
\hline \multirow{10}{*}{ 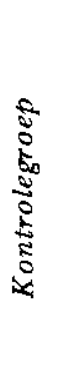 } & K 1 & & 40 & 25 & 15 & 40 & 20 & 20 \\
\hline & K 2 & & 30 & 20 & 10 & 30 & 15 & 15 \\
\hline & K 3 & & 20 & 25 & 5 & 30 & 15 & 15 \\
\hline & K 4 & & 40 & 25 & 15 & 30 & 15 & 15 \\
\hline & K 5 & & 30 & 10 & 20 & 30 & 15 & 15 \\
\hline & K 6 & & 30 & 10 & 20 & 30 & 15 & 15 \\
\hline & K 7 & & 20 & 10 & 10 & 30 & 10 & 20 \\
\hline & K 8 & & 30 & 10 & 20 & 30 & 10 & 20 \\
\hline & K 9 & & 30 & 10 & 20 & 20 & 10 & 10 \\
\hline & K10 & & 30 & 10 & 20 & 30 & 15 & 15 \\
\hline
\end{tabular}

Tabel II Spraakdiskriminasiewaardes.

vermoedelike negatiewe stimuli, aangebied in die vorm van spesifjeke woordelyste.

\section{Materiaal:}

i. Neutrale woorde: woorde wat as sodanig ge-evalueer is deur 'n groep proefpersone nadat dit d.m.v. 'n tachistoskoop aan hulle gebied is.

ii. Hakkelwoorde - woorde wat vir elke hakkelaar spesifieke ,hakkelwaarde" besit as gevolg van die voortdurende hakkelervaring, wat met negatiewe emosies geassosieer is.

Bogenoemde 2 groepe het aan bepaalde vereistes voldoen, nl.:

a. Eenlettergrepig - omdat drempelbepaling sodoende meer definitief is.

b. Die woorde moes onder die 1000 mees algemene Afrikaanse woorde voorkom (vereiste gestel deur Broadbent). 


\section{Metode}

1. Aan die proefpersone van die eksperimentele groep is 'n lys van 12 neutrale woorde (soos voorheen bepaal) gebied waaruit hulle alle potensiële hakkelwoorde moes elimineer. Indien nodig is 'n verdere aantal woorde deur die proefleier op 'n doelbewus-toevallige wyse uitgeskakel sodat 6 woorde oorgebly het wat as die neutrale stimulilys sou dien.

2. 'n Lys van 6 hakkelwoorde is saamgestel op grond van ondervraging en observasie van die proefpersone.

3. 'n Finale stimulus-lys is saamgestel, bestaande uit 6 hakkel- en 6 neutrale woorde. Die orderangskikking het berus op 'n toevallige metode deur die gebruik van ewekansige tabelle.

4. Die binourale drempelwaarde van elke woord is vervolgens bepaal d.m.v. die stygende metode wat in deskrete $5 \mathrm{~dB}$-stappe aangebied is.

5. Die stimulus-lys van die neutrale woorde asook 'n saamgestelde lys van die totale aantal hakkelwoorde soos verkry van al 10 die proefpersone van die eksperimentele groep, is ook aan die kontrolegroep gebied en hulle drempelwaardes bepaal.

\section{RESULTAAT}

Die resultate word in Tabel III uitgelê.

\begin{tabular}{|l|c|c|c|c|c|c|}
\hline \multirow{2}{*}{$\begin{array}{c}\text { Proef- } \\
\text { persone }\end{array}$} & \multirow{2}{*}{ G. } & \multicolumn{2}{|c|}{$\begin{array}{c}\text { Eksperimentele- } \\
\text { groep }\end{array}$} & \multicolumn{2}{c|}{ Kontrolegtoep } & \multirow{2}{*}{$\begin{array}{c}\text { Proef- } \\
\text { persone }\end{array}$} \\
\cline { 3 - 6 } & & $\begin{array}{c}\text { Neutrale } \\
\text { woorde }\end{array}$ & $\begin{array}{c}\text { Hakkel- } \\
\text { woorde }\end{array}$ & $\begin{array}{c}\text { Hakkel- } \\
\text { woorde }\end{array}$ & $\begin{array}{c}\text { Neutrale } \\
\text { woorde }\end{array}$ & \\
\hline & & & & & & \\
E 1 & M & 18,00 & 17,50 & 24,46 & 11,25 & K 1 \\
E 2 & M & 20,00 & 17,00 & 17,77 & 13,64 & K 2 \\
E 3 & V & 20,00 & 15,00 & 11,40 & 14,09 & K 3 \\
E 4 & M & 33,00 & 29,00 & 18,86 & 21,50 & K 4 \\
E 5 & M & 23,00 & 21,25 & 14,00 & 20,45 & K 5 \\
E 6 & M & 17,00 & 14,17 & 18,46 & 22,14 & K 6 \\
E 7 & M & 21,67 & 22,00 & 17,75 & 21,00 & K 7 \\
E 8 & V & 21,67 & 17,00 & 13,82 & 14,58 & K 8 \\
E 9 & V & 15,83 & 15,00 & 8,94 & 10,00 & K 9 \\
E10 & M & 15,00 & 12,00 & 14,00 & 14,09 & K10 \\
\hline
\end{tabular}

Tabel III Drempelwaardes in $d B$

Verwerking van hierdie gegewens is hoofsaaklik op twee vlakke gedoen nl.;

1. 'n Vergelyking tussen die eksperimentele groep se waamemingsdrempels vir neutrale en hakkelwoorde waartydens die nulhipotese verklaar dat daar geen verskil bestaan nie. Die resultate van die Wilcoxon-simmetrietoets toon 
wel 'n verskil op die 1\%-peil van betekenis en verwerp dus die nulhipotese. Dit wil sê, die eksperimentele groep vertoon 'n hoogs betekenisvolle verskil in drempelwaardes tussen die 2 lyste en wel in dié sin dat die waarnemingsdrempels van die negatiewe (hakkel) woorde betekenisvol laer is.

2. 'n Vergelyking tussen die kontrolegroep as waarnemingsdrempels vir neutrale en hakkelwoorde. Weereens up grond van die resultate verkry deur die Wilcoxon-simmetrietoets moet in hierdie geval verklaar word dat die nulhipotese nie verwerp kan word nie, d.i., daar kan nie 'n betekenisvolle verskil tussen die drempelwaardes vir negatiewe (hakkel) en neutrale woorde gevind word nie.

Gesien die betekenisvolle resultate van eksperiment 1 is enige verdere kruisvergelyking (bv., vergelyking tussen eksperimentele en kontrolegroep se hakkelwoorddrempelwaardes) moeilik uitvoerbaar en sal dit waarskynlik geen praktiese bydrae lewer nie. Dieselfde besware vir 'n vergelyking tussen die resultate van manlike en vroulike lede wat op eksperiment 1 ingebring is, geld ook hier en is dus nie deurgevoer nie. Wat die kwalitatiewe resultate betref, kan dit betekenisvol wees om op die volgende te let:

a) Die lede van die eksperimentele groep wat die grootste verskil in drempelwaarde vertoon $\mathrm{nl}$,, E3, E4, E8, is diegene wat, volgens die proefleier se mening (let wel: dit is nie statisties d.m.v. vergelykingsskale vasgestel nie) die ernstigste ritmiese versteurings vertoon. In hierdie geval word met ,ernstig' die frekwensie sowel as die graad van spanning tydens die onvlothede bedoel.

b) In teenstelling hiermee is die proefpersoon, E7, wat 'n negatiewe verskil tussen sy drempelwaardes vertoon, 'n hakkelaar wat deur geringe uiterlike spanning en min vlotheidsprobleme gekenmerk word.

c) Proefpersone E3 en E8 wat 2 uit die 3 lede is wat 'n groot verskil in drempelwaarde vertoon, is vroulike lede van die groep.

\section{AFLEIDINGS}

Om tot wilde bewerings in verband met ' $n$ definitiewe etiologie te kom op grond van hierdie resultate sou buitensporig wees. Nogtans wil dit voorkom asof die gegewens op 'n aantal aspekte lig kan werp:

1. Die feit dat die eksperimentele groep 'n betekenisvolle verskil in drempelwaarde tussen die negatiewe en hakkelwoorde vertoon, lei tot vrae in verband met die oorsaak hiervan. Aangesien in ag geneem is dat die 2 woordelyste homogeen is wat betref aspekte soos lengte (eenlettergrepig), bekendheid ( 1000 mees bekende woorde), en bewustheid (albei lyste is aan die proefpersoon gebied vóór die eksperiment) wil dit voorkom asof die oorsaak van die verskil by 'n ander faktor gesoek moet word.

Die outeur reken dat bekendheidskwaliteite moontlik nogtans 'n rol kan speel as in aanmerking geneem word dat die definiëring van ,hakkelwoord" soos volg daar uitsien: „Woorde warop jy gewoonlik of altyd sal hakkel”. Dit kan dus veroorsaak dat hierdie woorde, al is hul algemene gebruiksfrekwensie net. 
so hoog soos die neutrale woorde, tog vir die indiwiduele hakkelaar meer bekend sal wees.

Nogtans is hierdie verklaring nie voldoende nie en moet die bekendheidsfaktor ook met die emosionele kwaliteit saamhang. Dit is dus meer waarskynlik dat die verskil in drempelwaardes toegeskryf moet word aan die feit dat dit woorde is waarop gewoonlik gehakkel word, wat dus altyd gepaard gaan met sterk emosionele negatiewe ervarings en wat dus die waarnemingsdrempel op een of ander wyse sal beinvloed.

Gesien in die lig van die strydvraag omtrent die bestaan, al dan nie, van drempelwaardes is dit op hierdie stadium gewaagd om die resultate van hierdie eksperiment toe te skryf aan die verskynsel van subliminale persepsie en perseptuele sensitiwiteit (Def.: die waarnemer reageer diskriminerend op die emosionele aspekte van 'n stimulus wat subliminaal aangebied word en wel in dié sin dat emosioneeldreigende stimuli makliker waargeneem word. ${ }^{1,6}$ )

Nogtans is dit moontlik en wenslik om dit vergelykbaar te stel aan 'n verdedigingsmeganisme sg., aan perseptuele ingestemdheid. Dit kan dan gedefinieer word as: 'n hoogs algemene toestand van gereedheid in die warnemer om selektief te reageer op klasse van gebeure in sy omgewing.

Dit sou interessant wees om te sien op watter wyse hierdie bevindings in verband gebring kan word met faktore soos: erns van die probleem, prognose, persoonlikheid en algemene lewensaanpasbaarheid van die indiwidu.

2. Bepaalde disfemie-kenmerke kan met hierdie resultate in verband gebring word bv.:

a) Die hakkelaar se vermoë om moeilike woorde en selfs situasies vooraf ,,aan te voel" op 'n stadium wat dit nog nie werklik sy bewussynsveld betrek het nie.

b) Aan die anderkant kan dit ook verband hou met die hakkelaar se skynbare onbewustheid van sekondêre simptome, en selfs met die verskynsel van onwaarneembaarheid. ${ }^{5}$ Die energiekonsentrasie en waarnemingsensitiwiteit word gerig op die gevreesde woord, aangesien dit vir hom die essensie van sy probleem is en kan lei tot 'n afname in die waarnemingsvermoëns op ander vlakke.

3. Hierdie resultate kan ook ten nouste in verband gebring word met terapieresultate. Op hierdie stadium sal alle spraakterapeute wat in die praktyk staan onomwonde verklaar dat die,grootste struikelblok vír habilitasie van die disfemie, die korrekte gebruik van voorbereidende instellings tydens sosiale situasies is. Waar 'n verdedigingsmeganisme (in hierdie geval die ,,vooraf ingestemdheid jeens die woord") as 'n wyse van aanpassing aan die gemeenskap is, kan dit miskien as 'n onmoontlikheid beskou word om van die hakkelaar te verwag om die resultaat van hièrdie aanpassing te modifiseer ten einde beheer oor sy spraak te verkry. Aan die ander kant kan dit dus ook as 'n prognostiese teken met betrekking tot die mate waartoe beheertegnieke wel sal slaag, beskou word. 


\section{EKSPERIMENT III}

Doel: Die vasstelling van die moontlike bestaan van onwaarneembaarheid (,imperceptivity" - volgens Froeschels: ,shut in to such a degree that they did not perceive certain signals which they perceive normally..."5) van betekenisvolle stimuli by die hakkelaar tydens 'n hakkelperiode.

\section{Materiaal:}

Potlood en blankopapier. Dieselfde woordelyste soos gebruik in Eksperiment II wat bestaan uit 6 neutrale en 6 hakkelwoorde met 'n verandering in die volgorde van aanbieding.

\section{Metode}

1. Die proefpersone van die eksperimentele groep is gekeur op grond van aard van hulle spesifieke vlotheidsversteurings. Slegs dié persone is gebruik wat so 'n lang hakkelperiode as simptoom vertoon dat hulle ten tye daarvan suksesvol met 'n woord gestimuleer kan word. Eventueel is 5 proefpersone gebruik.

2. Gegrond op die gegewens van Eksperiment $I$ is al die proefpersone se mees gemaklike luidheid, binouraal, vir spraakwaarneming bepaal.

3. Die proefpersone is opgedra om oor te gaan tot 'n spontane lang beskrywingsreaksie (bv. „Beskryf die pad wat $u$ moet ry vanaf $u$ huis tot by die Spraakkliniek"). Hiertydens is dan van die proefpersone verwag om te luister vir die voorkoms van bepaalde stimuluswoorde, om indien hulle dit hoor, te reageer deur die woord neer te skryf, en om dit verder te ignoreer en aan te gaan met die ,gesprek".

4. Tydens die beskrywingsituasie is die stimuluswoord aangebied sodra 'n hakkelperiode voorgekom het en net nadat dit begin is. Vir hierdie doel is die hakkelperiode gedefinieer as ,What the onlooker observes is the so-called stuttering block ... repetition, prolongation or a complete cessation of sound". 3

5. Bogenoemde resultate is kwalitatief aangevul d.m.v. gesprekke en vraelyste waartydens gepoog is om vas te stel of waarnemingsprobleme tydens die hakkelperiode ondervind is.

RESULTAAT

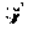

Die resultate word in Tabel IV uitgelê.

Gesien die klein getal proefpersone is dit in hierdie geval onwenslik gereken om die gegewens statisties te verwerk. Oor die algemeen kan die volgende gevolgtrekkings gemaak word:

i. Uit die 5 proefpersone het al 5 tenminste een defektiewe waarneming gemaak (met defektief word sowel verkeerde as geen waarneming bedoel); 


\begin{tabular}{|c|c|c|c|c|c|c|}
\hline & \multirow{2}{*}{$\begin{array}{c}\text { Proef- } \\
\text { persone }\end{array}$} & $\begin{array}{c}\text { Aangebode } \\
\text { stimuli } \\
\text { (woorde) }\end{array}$ & $\begin{array}{c}\text { Aant. } \\
\text { woorde } \\
\text { korrek } \\
\text { waargeneem }\end{array}$ & \multicolumn{2}{|c|}{$\begin{array}{c}\text { Aant. woorde } \\
\text { verkeerd waar- } \\
\text { geneem }\end{array}$} & \multicolumn{2}{|c|}{$\begin{array}{c}\text { Aant. woorde glad } \\
\text { nie waargen eem } \\
\text { nie }\end{array}$} \\
\cline { 4 - 6 } & & $\begin{array}{c}\text { Neutrale } \\
\text { woorde }\end{array}$ & $\begin{array}{c}\text { Hakkel- } \\
\text { woorde }\end{array}$ & $\begin{array}{c}\text { Neutrale } \\
\text { woorde }\end{array}$ & $\begin{array}{c}\text { Hakkel- } \\
\text { woorde }\end{array}$ \\
\hline E 1 & 12 & 8 & 2 & 2 & & \\
E 2 & 12 & 9 & 2 & 1 & & \\
E 3 & 12 & 11 & 1 & & & \\
E 4 & 12 & 8 & & 2 & 1 & 1 \\
E 5 & 12 & 10 & 1 & 1 & & \\
\hline
\end{tabular}

Tabel IV Getal stimuluswoorde wat ouditief aangebied word tydens die spontane spraak van hakkelaars.
46
ii. $60=76,7 \%$ van die stimuliwoorde is korrek waargeneem;
iii. $\frac{12}{60}=20 \%$ is foutief wargeneem;
iv. $\frac{2}{60}=3,33 \%$ is glad nie waargeneem nie;
v. 7 hakkel en 7 neutrale woorde is defektief waargeneem.

\section{AFLEIDINGS}

1. As bogenoemde syfers in aanmerking geneem word wil dit voorkom asof daar nie in hierdie eksperiment bewys gelewer is van die bestaan van onwaarneernbaarheid tydens die hakkelperiode nie.

2. Dit skyn asof die aard van stimulus (hakkel/neutrale woord), met betrekking tot sy emosionele kwaliteit nie met onwaarneembaarheid in verband gebring kan word nie.

Voor die uitvoering van die eksperiment is gemeen dat hierdie gegewens beslis 'n verskil sal vertoon en wel t.o.v., 'n groter onwaarneembaarheid van hakkelwoorde. Die voorlopige hipotese wat gestel is, het verklaar dat onwaarneembaarheid verband kan hou met die aspek van perseptuele weerstand d.w.s., onwaarneembaarheid van dreigende stimuli wat bo die drempel. aangebied word.

Bogenoemde gegewens kan op hierdie stadium nie die hipotese verwerp of aanvaar nie, aangesien die steekproef te klein was. Oor die algemeen egter wil dit voorkom asof die hakkelaar nie onwaarneembaarheid ervaar tydens die hakkelperiode vir betekenisvolle spraakstimuli nie.

3. Hierdie resultate is egter nie finaal nie, veral as in anmerking geneem word dat alle proefpersone tydens die verloop van die eksperiment verklaar het:

a) dat dit moeilik was om die woorde te hoor; 
b) dat hulle dit oor die algemeen moeilik vind om stimuli waar te neem tydens die hakkelperiode.

\section{BIBLIOGRAFIE}

1. Bánréti Fuchs, K.M. (1964) Problemen der Subliminale Perceptie. Von Gorcum en Comp. Nederland.

2. Davids, A. (1956) Past experience and Present Personality Disposition as determinants of selective auditory Memory $J$. of Personality. 25 , No. 1 , 19-26.

3. Eisenson, J. (Ed) (1958) Stuttering: A Symposium. Harper and Row, Publishers, New York.

4. Freund, H. (1966) Psychopathology and the Problem of Stuttering. Charles C. Thomas, Illinois.

5. Froeschels and Rieber, R.W. (1963) The Problem of Auditory and Visual Imperceptivity in Stutterers, Folia Phoniatrica, 15, No. 1, 13-19.

6. Howie, D. (1952) Perceptual Defense Psychological Review. 59, 308-315.

7. Mussen, P.H. Rosenzweig, M.R. (1969) Annual Review of Psychology. 20.

8. Selected papers of Emil Froeschels. (1964) North-Holland Publishing Co. Amsterdam, 1964.

9. Sapir, E. (1949) Language, Harcourt, Bruce \& Co. 